\title{
Atherosclerosis and Metabolic Syndrome-significance of Inflammation, Urgency of Weight Loss and Extracorporeal Removal of Proinflammatory and Proatherogenic Substances
}

Nazirov FG, Khaybullina ZR* and Sharapov NU

Republican Specialized Center of Surgery, Named after Academician V. Vakhidov, Tashkent, Uzbekistan

*Corresponding author: Khaybullina ZR, Republican Specialized Center of Surgery, Named after Academician V. Vakhidov, Tashkent, Uzbekistan, Tel: + 99871 239-47-95; E-mail: zrkhaybullina1@gmail.com

Received date: November 02, 2017; Accepted date: November 20, 2017; Published date: November 27, 2017

Copyright: (c) 2017 Khaybullina ZR, et al. This is an open-access article distributed under the terms of the Creative Commons Attribution License, which permits unrestricted use, distribution, and reproduction in any medium, provided the original author and source are credited.

\begin{abstract}
The link between atherosclerosis and metabolic syndrome is through system inflammation. Molecular mechanisms of this link can be explained by hypothesis that arterial hypertension, central obesity and insulin resistance are connected through dysfunction of endothelium and inflammation, where major role play tumor necrosis factor alpha (TNF-a) and reactive oxygen species (ROS), that promotes modulation of insulin receptor substrare2 (IRS2) signaling, insulin resistance, nuclear factor NF-kB (NF-kB) and IkB kinase $\beta$ activation, endothelial dysfunction, oxidized low density lipoproteins accumulation, vascular inflammatory responses with vascular smooth muscular cells apoptosis and atherosclerotic plaque instability. TNF-a and ROS overproduction closely linked with central obesity and adipocytokines deregulation. Morphological substrate of atherosclerosis-plaque, it's stability and evolution depends on intensity proinflammatory mediators and matrix metalloproteinases production, that closely bind with metabolic syndrome components, such as central obesity with adipocytokines production; arterial hypertension with endothelial dysfunction; glucose intolerance, insulin resistance and its intracellular signaling disturbances; oxidized low density lipoproteins accumulation and oxidative stress.
\end{abstract}

Keywords: Atherosclerosis; Metabolic syndrome; Inflammation; Extracorporeal removal of proinflammatory substances

\section{Introduction}

Critical role of inflammation and oxidative stress at atherosclerosis and metabolic syndrome caused urgency of weight loss, proinflammatory and proatherogenic molecules deletion for prevention of atherosclerosis progression. Inflammation is common for ischemic heart disease, stroke and obesity, it is thought to be a sign or atherogenic response. On the base of 20 studies results (49097 patients) it has been established significant link between concentration of high sensitivity C-reactive protein (hs-CRP), fibrinogen, white blood cells (WBC) count, monocytes count and atherosclerotic plaque formation, which was evaluated according intima-media thickness (cIMT) $[1,2]$. This data suggest WBC recruitment and expression of pro-inflammatory cytokines both at early atherogenesis and atheroma formation. Inflammatory mechanisms couple dyslipidaemia to atheroma formation, promote thrombosis and late complication of atherosclerosis as myocardial infarctions and stroke [3,4], C-reactive protein (CRP) and interleukin-6 (IL-6) level can be used for prediction of major cardiovascular events, matrix metalloproteinases (MMP) can be useful as markers of plaque instability [5]. Fibrinogen, serum amyloid A, IL-6, and lipoprotein-associated phospholipase A2 (LpPLA2) have been proposed as tools for risk assessment in patients with carotid artery atherosclerosis and approved as a predictor of ischemic stroke $[6,7]$, hs-CRP level was shown to predict the risk of stroke in several large epidemiological studies [8]. There are some specific markers of atherosclerotic inflammation such as long pentraxin-3 and calcium binding protein involved in inflammatory signaling- S100A12, that can be associated with the presence of atherosclerotic plaques and prevalent vascular disease [9-11]; adhesion molecules, expressed on leukocytes surface like L-selectin and serum levels of tumor necrosis factor alpha (TNFa) have been associated with larger plaque size [12].

Cytokines are expressed by all types of cells involved in atherosclerotic plaque formation and performed crosstalk among vascular residing cells, endothelial and smooth muscle cells, leucocytes. Significance of proinflammatory cytokines as messengers "provided a mechanism whereby risk factors for atherosclerosis can alter arterial biology, and produce a systemic milieu that favors atherothrombotic events" [13]. There are some researches that supposed the production of highly specific antibodies against key molecules involved in the perpetuation of the inflammatory cascade, raising hope for advances in the treatment of atherosclerosis [14]. Drugs such as statins, aspirin, methotrexate, and colchicine act in an immunomodulatory way and cytokines production that may beneficially affect atherogenesis and/or cardiovascular disease progression. Inflammatory markers involved in vascular inflammation stimulate the generation of endothelial adhesion molecules, proteases, and other mediators, which may enter the circulation in soluble form [15].

Morphological substrate of atherosclerosis-plaque, it's stability and evolution depends on intensity proinflammatory mediators and MMP production, that closely bind with metabolic syndrome (MetS) components, such as central obesity with adipocytokenes production; arterial hypertension with endothelial dysfunction; glucose intolerance, insulin resistance and its intracellular signaling disturbances; oxidized low density lipoproteins accumulation and oxidative stress.

The link between atherosclerosis and metabolic syndrome is through system inflammation, that approved IDF in "Platinum 
Citation: Nazirov FG, Khaybullina ZR, Sharapov NU (2017) Atherosclerosis and Metabolic Syndrome-significance of Inflammation, Urgency of Weight Loss and Extracorporeal Removal of Proinflammatory and Proatherogenic Substances. Cardiovasc Pharm Open Access 6: 227. doi:10.4172/2329-6607.1000227

Page 2 of 6

standart" of metabolic disorders at atherosclerosis, that include evaluation of pro-inflammatory state (IL-6, TNF-a), adipocytokines (leptin, adiponectin), HOMA-IR, free fatty acid, markers of endothelial dysfunction and prothrombotic state (PAI-1, fibrinogen), hormones of pituitary-adrenal axis at MetS patients [16]. Molecular mechanisms of this link can be explained by hypothesis that arterial hypertension, central obesity and insulin resistance are connected through dysfunction of endothelium and inflammation, where major role plays TNF-a, NO depletion and peroxynitrite and ROS overproduction.

Both insulin resistance and visceral obesity accompanied by TNF-a overproduction in adipocytes. TNF-a can bind 2 types of receptors: TNFR1and TNFR2, which is expressed on all types of cells. TNFRI triggers both apoptosis and proliferation, as well as differentiation of cells, while TNFRII triggers metabolic effects of TNF-a. TNF-a can inhibit phosphorilation of serine in insulin receptor substrate (IRS1) and inhibit phosphorilation of alpha subunit of insulin receptor itself, that caused disturbances of insulin signal transduction; TNF-a inhibit expression of GLUT-4 and lipoprotein lipase genes [17]. Insulin overproduction and insulin resistance promotes mitogen-activated protein-kinase (MAP-kinase) activation that induced endothelin-1 production; these changes are previous to atherosclerotic plague formation [18].

It is established, that anti-inflammatory and anti-atherogenic properties of a wall of a vessels are determined by normal functioning of endothelium and its ability to NO production, that have a lot of functions, autocrine and paracrine action [19]. In cells of endothelium NO suppresses nuclear factor $\mathrm{kB}(\mathrm{NF}-\mathrm{kB})$, that regulates proinflammatory genes expression [20], by this way NO cause decreasing production of endotelin-1, monocytes chemoattractant protein (MCP-1), superoxide-radical, adhesion molecules. Hyperglycemia and accumulation of advanced glycation-end products can activate NF-kB and MAP-kinase pathways, while insulin and insulin growth-factor receptors are implicated in the activation of protein kinase B (Akt) and extracellular-signal-regulated kinases 1/2 (ERK1/2) [21]; NF-kB is also responsible of increased susceptibility of vascular smooth muscle cells to pro-apoptotic stimuli through miR-133a levels [22]. IкB kinase $\beta$ (IKK $\beta$ ), a central coordinator of inflammatory responses through activation of $\mathrm{NF}-\kappa \mathrm{B}$, has been implicated in vascular pathologies, IKK $\beta$ functions in smooth muscle cells to regulate vascular inflammatory responses and atherosclerosis development [23].

Insulin resistance (IR) is accompanied by decreasing of IRS2 expression, that caused increasing of MCP1 defects in Akt2 and Ras/ ERK1/2 signaling pathways, that may contribute to accelerated atherosclerosis in MetS states [24]. IR increases plaque vulnerability by augmenting the inflammatory chemokine fractalkine and its receptor axis, which is mechanistically linked to reduced vascular smooth muscle cells survival and atheroma plaque destability; modulation of IRS2 signaling may be potential therapeutic target for reduction of inflammatory mediators at IR-MetS patients [25]. It is well known, that insulin signaling cascade is necessary for cell growth, metabolism, and survival through the activation of both MAP-kinases and phosphatidylinositide-3-kinase (PI3K), where PI3K pathway associated with IRS1 and IRS2, subsequent Akt $\rightarrow$ Foxo1 phosphorylation cascade has a central role in the control of nutrient homeostasis and organ survival [26]. The inactivation of Akt and activation of Foxo1, through the suppression IRS1 and IRS2 in different organs following hyperinsulinemia, metabolic inflammation, and overnutrition, may act as the underlying mechanisms for the metabolic syndrome in humans [27]. IRS1 is down-regulated in states of insulin resistance, the IGF-I receptor signals pass through an alternate scaffold protein, SHPS-1, resulting in pathophysiologic stimulation of vascular smooth muscle cell migration and proliferation, resulting developing of macrovascular complications [28]. Insulin suppresses several proinflammatory transcription factors: NF-kB, Egr-1, activating protein-1 (AP-1) and the corresponding genes regulated by them, such as matrix metalloproteinase-9, PAI-1. Insulin can suppress reactive oxygen species generation and $\mathrm{p} 47$ phox expression, to increase inhibitor (I)- $\mathrm{kB}$ expression in mononuclear cells as well as to suppress plasma concentrations of intracellular adhesion molecule-1 and MCP-1 and CRP level [29]. Insulin modulates the regulation of proliferation of vascular smooth-muscle cells (VSMC) with particular emphasis on PI3K/Akt, cPLA2 and ERK1/2 signaling pathways that have been identified as important mediators of VSMC hypertrophy and vascular diseases [30]. Insulin has anti-inflammatory and antiapoptotic effects [31]. Beneficial cardiovascular effects of incretin mimetic drugs, enchancing insulin secretion, and dipeptidyl peptidase-4 (DPP-4) inhibitors, approves insulin significance for prevention of atherosclerosis [32].

Hyperglycemia, oxidized atherogenic lipoproteins, and advanced glycation end products are linked to oxidative stress in diabetes: overproduction of ROS after NADPH oxidase activation or mitochondrial dysfunction is associated with peroxinitrite synthesis, NO concentration decreasing and endothelial-dependent vasodilation disturbances; glycated LDL-induced expression of plasminogen activator inhibitor-1 in endothelial cells and endothelial disfunction development [33]. Hyperglycemia-induced oxidative stress and ROS overproduction promotes endothelial dysfunction, that increase proinflammatory and pro-coagulant factors expression, induce apoptosis and impair NO release; induces several phenotypic alterations also in VSMC; ROS is one of the factors that can promote both VSMC proliferation/migration in atherosclerotic lesions and VSMC apoptosis, which is potentially involved in atherosclerotic plaque instability and rupture [34]. Hyperglycemia induces vascular damage probably through a single common pathway-increased intracellular oxidative stress-linking four major mechanisms, namely the polyol pathway, advanced glycation end-products (AGEs) formation, the protein kinase C (PKC)-diacylglycerol (DAG) and the hexosamine pathways [35].

Central obesity connected with atherosclerosis by insulin resistance and disturbances of adipocytokines production (leptin and rezistin overproduction, adiponectin deficiency), that can promote phosphatidil-inositol-3-kinase (Akt-kinase) pathway activation [36]. Leptin stimulates MCP-1 synthesis via the MAP-kinase/ERk1/2 pathway through phosphorylation of MAC and E26-like transcription factor [37]. Cytokines production can be disturbed at MetS due aberrant methylation of different genes, such as genes of IL-6, TNF- $\alpha$, mitochondrial transcription factor $\mathrm{A}$, and glucose transporter- 4 (GLUT4), which involved in inflammation and oxidative stress. Also some of atherogenic transcription factor (cMYC, TLR2, CXCR4), which regulated pro-inflammatory genes of paraoxonase, interferon regulatory factor-1, toll-like receptors, CXCR4 and SOD1 are overexpressed in monocytes at obesity; weight loss associated with a concomitant decrease of their expression [38].

So, inflammatory mediators closely connected with major factors, associated with atherosclerosis and MetS [39]. Insulin resistance via proinflammatory effects leads to several macrovascular and microvascular alterations that influence the progression of 
Citation: Nazirov FG, Khaybullina ZR, Sharapov NU (2017) Atherosclerosis and Metabolic Syndrome-significance of Inflammation, Urgency of Weight Loss and Extracorporeal Removal of Proinflammatory and Proatherogenic Substances. Cardiovasc Pharm Open Access 6: 227. doi:10.4172/2329-6607.1000227

Page 3 of 6

development of atherosclerosis. Extracorporeal removal from blood some of proinflammatory cytokines and proatherogenic substances may be effective for prevention of atherogenesis progression. Identifying the triggers for inflammation and unraveling the details of inflammatory pathways may eventually furnish new therapeutic targets. Also overweight and dislipidemya should be corrected.

Chylomicrones (CM) and low density lipoproteins (LDL) have specific proatherogenic and proinflammatory properties [40,41], the concentration of small low-density lipoprotein (sLDL) has been associated with the progression of coronary and carotid atherosclerosis and increased cardiovascular risk, that has been approved in casecontrol and prospective studies [42,43]; "the lipoprotein cholesterol profile and the LDL floatation rate (LDL-RF) were directly and significantly correlated with weight, body mass index, waist, hip, waist/hip ratio, triglycerides, fasting glycaemia, cIMT and inversely related to high-density lipoprotein (HDL)" [20]; CM and small LDL were associated with a proinflammatory activation of peripheral mononuclear and endothelial cells [44]. CM and other triglyceriderich lipoproteins induce expression of adhesion molecules, cyclooxygenase- 2 and heme-oxygenase- 1 in endothelial cells, and activate intracellular signaling pathways involving MAP-kinases, NF$\kappa \mathrm{B}$ and Nrf2 [45].

Oxidized low density lipoprotein (oxLDL) induced injury of endothelial cells is considered to be the first step in the pathogenesis of atherosclerosis: oxLDL significantly decreased cell viability, increased LDH and IL-8 release, inhibited NO production, and induced cyclooxygenase 2 expression; OxLDL stimulated the expression of its specific receptors-lectin-like low-density lipoprotein receptor-1 (LOX-1) and overproduction of ROS; also oxLDL induces phosphorylation of p38MA-kinase, the dephosphorylation of $\mathrm{PKB}$, activation of NF- $\kappa B$, and the degradation of I $\kappa B$ [46]. LOX-1 promotes the generation of superoxide anion, the inhibition of NO production and the increment of endothelial adhesiveness to monocytes [47]. Binding OxLDL to LOX-1 significantly increases generation of ROS that make pathological loop, suggesting ROS overproduction caused oxidized LDL formation. Molecular mechanisms of this changes includes Lp-PLA2 activation and lysophosphatidylcholine and oxidized nonesterified fatty acids formation, that can elicit several deleterious inflammatory and oxidative responses, because lysophosphatidylcholine serves as a potent chemoattractant for monocytes, resulting in foam cell accumulation within the arterial wall membrane destructive processes [48]. Superoxide radical induced both oxidative and inflammatory pathways, as well as endothelial dysfunction. So, it can activate major proinflammatory transcriptional factors: NF-kB and AP-1, it can diminished bioavailability of NO due binding NO with formation of high toxic peroxynitrite. Increasing of ROS generation induced hydrogen peroxide and the hydroxyl radical cytotoxic and cytopathic effects, such as membrane phospholipids peroxidation, DNA damage and denaturation of proteins/enzymes [49]. oxLDL induces endothelial cell proliferation via Rho/ROCK/Akt/ p27kip1 signaling: opposite effects of oxLDL and cholesterol loading [50].

In hyperlipidemic conditions, cholesterol accumulates in macrophages disrupting cholesterol trafficking and leading to an inflammatory environment [51,52]. C1q plays a dual role in atherosclerosis. $\mathrm{Clq}$ polarizes macrophages to a protective phenotype in the early stages of atherosclerosis by increasing anti-inflammatory cytokines and decreasing pro-inflammatory cytokines, leading to a reduction in disease markers such as cholesterol and triglyceride levels and atherosclerotic lesion size [53,54]. oxLDL-induced endothelial stiffening is mediated by the CD36-dependent activation of RhoA and its downstream target Rho kinase via inhibition of myosin light-chain phosphatase (MLCP) and myosin light-chain (MLC)2 phosphorylation that associated with increased endothelial angiogenic activity, induce endothelial cell stiffening and promote capillary formation [55]. oxLDL-induced Rho/Akt signaling downregulated cell cycle inhibitor p27kip1 Preloading these cells with cholesterol, however, prevented oxLDL-induced Akt phosphorylation and HAEC proliferation [50]. Vascular-endothelial grows factor (VEGF) modified macrophages significantly decreased cytoplasmic lipid accumulation after treatment with oxidized LDL (ox-LDL). Moreover, down-regulation of CD36 expression in these cells was probably one of the mechanisms of reduction in foam cell formation [56].

It is established that cholesterol reduction linked with entity of LDL and the disappearance of wall features of inflammation, visualized in MRI [57]. According results of dal-PLAQUE study, modulation of cholesterol ester transfer protein activity to raise HDL after 6 months by Dalcetrapib treatment significantly reduced alteration of FDG TBR carotid artery segment [58].

For asymptomatic patients with atherosclerosis evaluation of inflammatory and immune profiles can be useful for stratification the risk of stroke, and also for estimation of stroke recurrence's risk [59], while carotid IMT can be useful for monitoring of the regression of the atherosclerotic process after medical treatment with statins and calcium-antagonists [15].

So, atherosclerosis closely connected to hyperlipidemia and inflammation, that suggest deep relation of atherosclerosis to metabolic status, which characterizes by insulin resistance and adipocytokines (adiponectin, leptin, resistin, PAI-1) deregulation. That can escalates the risk of cardiovascular diseases due MetS involvement [60].

How it has been established in our previous work, loss of weight can restore metabolic disorders and decrease inflammation [61] at obese and MetS patients. It is important to have attention that some of patients might not be compliant to hypolipidemic treatment and fitness, some of them have very high LDL levels (more than $300 \mathrm{mg} /$ $\mathrm{dl}$ ). In these cases the extracorporeal removal of proatherogenic substances may be useful to restore normal lipidomic profile and physiologic metabolites concentration [62]. Selective LDL sorption from whole blood or plasma can be effective, because reduction of total cholesterol and apo proteins apo-B100 is $35-80 \%$; also TNF-a concentration can be decreased after procedure; the most popular sorption systems for LDL purification are "Liposorber L" and “Liposorber D' (Kaneka, Japan), "LDL Lipopak (POKARD, Russia), "LDL TheraSorb" (Milteney, Germany), DALI (Fresenius, Germany) and LNP 45 (Tosoh, Japan); "LDL-300", "LDL- Lipopac" have high selectivity, biocompatibility and stability; the maximal total cholesterol and apoB100-binding capacity is found at "SFM-LPM", LDL-45 and "LDL-Lipopac" [63-65]. Purification of TNF-a is necessary, because TNF-a induce low grade inflammation in adipose tissue, increase resistance to insulin and intensity of carbohydrates metabolism [66], increase expressions of the adhesive molecules on surfaces of endothelium, granulocytes and so mediated disseminated blood clotting [15], it is strong inhibitor of eNOS, activator of ROS [67]. Nonselective sorption of TNF-a provides sorption system, containing alpha-2 macroglobulin [68]. 
Citation: Nazirov FG, Khaybullina ZR, Sharapov NU (2017) Atherosclerosis and Metabolic Syndrome-significance of Inflammation, Urgency of Weight Loss and Extracorporeal Removal of Proinflammatory and Proatherogenic Substances. Cardiovasc Pharm Open Access 6: 227. doi:10.4172/2329-6607.1000227

Page 4 of 6

We have studied IL-6, TNF-a, CRP, malon dyaldehyde and VEGF, lipidomic profile in blood serum of the patients with morbid obesity and after laparoscopic sleeve gasterectomy (LSG). We have established, that LSG cause not only weight loss, but reduction of proinflammatory factors in blood 3 months after surgery. Our previous study has shown that after LSG body mass index and waist circumference decreasing on $25 \%$ and $14 \% 3$ month after surgery versus data before treatment, normalizations of lipidomic profile and glucose were observed 2 week after the surgery [61]. However, ways of liquidation of inflammatory process and oxidative stress at an atherosclerosis have not found yet, probably, since of heterogeneity of trigger factors of the systemic inflammatory response and ROS generation.

We have observed 377 patients with atherosclerosis and MetS. It has been established that central obesity is the most frequent component of MetS at patients with ischemic heart disease and atherosclerosis. At patients with coronary atherosclerosis (CA) waist circumference increasing has been shown in $94 \%$, HDL decreasing-in $89 \%$, arterial hypertension-in $79 \%$, glucose intolerance-in $52 \%$. At patients with peripheral atherosclerosis (in iliac-femoral arterial pool)-PA the most frequent component of MetS was arterial hypertension-in $76 \%$, hypertriglyceridemia-in $73 \%$, glucose intolerance-in $43 \%$.

At coronary atherosclerosis we have founded strong positive correlative links between CRP and glucose level in blood, between CRP and triglycerides; correlative link between CRP and MDA was $(r=0.6, p<0.05)$. PA characterizes by increasing of IL- 6 and VEGF. This data suggests that inflammation at $\mathrm{PA}$ is acute, due to local inflammatory reaction of peripheral tissues after chronic ischemia. CA is associated with decompensate oxidative stress and low grade inflammatory reaction, correlating with metabolic disorders such as increasing of body mass index and glucose concentration $[69,70]$.

We have evaluated level of proinflammatory factors and oxidative stress markers after percutaneous coronary intervention (stenting) and coronary bypass operations $(\mathrm{CBO})$ at ischemic heart disease patients. MDA and CRP levels hasn't changed early after coronary stenting, but increased on $49 \%$ and $508 \%$ respectively after coronary bypass operations. TNF-a was increased both after stenting and coronary bypass on $39 \%$ and $110 \%$ respectively versus preprocedural level. Correlation link MDA/TNF-a have overage force $(r=0.53, p<0.05)$ after $\mathrm{CBO}$, whereas after coronary stenting it was weak $(\mathrm{r}=0.11, \mathrm{p}>0.05)$. IL-6 and VEGF concentration decreases after stenting (on 1.5 and 2.2 times versus preprocedural) and significantly increases at 30 -th day after CBO (1.3 and 10.1 times versus preprocedural, $\mathrm{p}<0.05)$. This data suggest that coronary revascularization by stenting does not accompanied by ROS overproduction and inflammation; neointimal proliferation and intracellular matrics remodeling decreases after stenting. Coronary bypass operations leads reinforcement of inflammatory response and ROS generation, that causes prolonged oxidative stress. In this conditions neo angiogenesis activation, approved by VEGF increasing, may be broken. Inflammation and oxidative stress after coronary bypass operations can have influence to outcomes of treatment [71].

\section{Conclusion}

The link between atherosclerosis and metabolic syndrome is through system inflammation. Molecular mechanisms of this link can be explained by hypothesis that arterial hypertension, central obesity and insulin resistance are connected through dysfunction of endothelium and inflammation, where major role play TNF-a and
ROS, that promotes modulation of IRS2 signaling, insulin resistance, $\mathrm{NF}-\mathrm{kB}$ and IкB kinase $\beta$ activation, endothelial dysfunction, oxidized low density lipoproteins accumulation, vascular inflammatory responses with vascular smooth muscular cells apoptosis and atherosclerotic plaque instability. TNF-a and ROS overproduction closely linked with central obesity and adipocytokines deregulation.

Our data has shown that MetS and atherosclerosis at obese patients and at patients with ischemic heart disease is accompanied with systemic inflammation, ROS, TNF-a, IL-6 overproduction. Loss of weight can restore metabolic disorders and decrease inflammation at obese and MetS patients, while coronary stenting and coronary bypass operation does not influence to oxidative stress and inflammation reduction. Inflammation and oxidative stress after coronary bypass operations can have influence to outcomes of treatment. Critical role of inflammation and oxidative stress at atherosclerosis and metabolic syndrome caused urgency of weight loss, proinflammatory and proatherogenic molecules deletion for prevention of atherosclerosis progression.

\section{Acknowledgement}

This work is made with support of grant SSV-MUZ-AD-006 "Development of the new filter from polymeric material, being necessary component for sorption systems of extracorporeal removal of toxic substances".

\section{References}

1. Willeit P, Thompson SG, Agewall S (2014) Inflammatory markers and extent and progression of early atherosclerosis: meta-analysis of individual-articipant-data from 20 prospective studies of the PROG-IMT Collaboration. Eur J Preventive Cardiology.

2. Chapman CML, Beilby JP, McQuillan BM, Thompson P, Hung J (2000) Monocyte count, but not C-reactive protein or interleukin-6, is an independent risk marker for subclinical carotid atherosclerosis. Stroke 35: 619-1624.

3. Libby P (2002) Review article Inflammation in atherosclerosis. Nature 420: 868-874.

4. Bentzon JF (2016) Targeting Inflammation in Atherosclerosis. J Am Coll Cardiol 68: 2794-2796.

5. Ammirati E, Moroni F, Norata GD, Magnoni M, Paolo GC (2015) Markers of Inflammation Associated with Plaque Progression and Instability in Patients with Carotid Atherosclerosis. Mediators of Inflammation.

6. Pohjantahti MH, Palomaki A, Kankkunen P, Husgafvel S, Knuth T, et al. (2011) Arterial elasticity and oxidized LDL among men with metabolic syndrome and different 10-year cardiovascular risk estimated by FINRISK and SCORE models. Annals of Medicine.

7. Nambi V, Hoogeveen RC, Chambless L (2009) Lipoprotein-associated phospholipase A2 and high-sensitivity C-reactive protein improve the stratification of ischemic stroke risk in the atherosclerosis risk in communities (ARIC) study. Stroke 40: 376-381.

8. Rost NS, Wolf PA, Kase CS (2001) Plasma concentration of C-reactive protein and risk of ischemic stroke and transient ischemic attack: the Framingham Study. Stroke 32: 2575-2579.

9. Knoflach M, Kiechl S, Mantovani A, Cuccovillo I, Bottazzi B, et al. (2012) Pentraxin-3 as a marker of advanced atherosclerosis results from the Bruneck. PLoS One 7: e31474.

10. Baragetti A, Knoflach M, Cuccovillo I (2014) Pentraxin 3 (PTX3) plasma levels and carotid intima media thickness progression in the general population. Nutrition Metabolism and Cardiovascular Diseases 24: 518-523. 
Citation: Nazirov FG, Khaybullina ZR, Sharapov NU (2017) Atherosclerosis and Metabolic Syndrome-significance of Inflammation, Urgency of Weight Loss and Extracorporeal Removal of Proinflammatory and Proatherogenic Substances. Cardiovasc Pharm Open Access 6: 227. doi:10.4172/2329-6607.1000227

Page 5 of 6

11. Abbas A, Aukrust P, Dahl TB (2012) High levels of S100A12 are associated with recent plaque symptomatology in patients with carotid atherosclerosis. Stroke 43: 1347-1353.

12. Andersson J, Sundström J, Kurland L (2009) The carotid artery plaque size and echogenicity are related to different cardiovascular risk factors in the elderly: the prospective investigation of the vasculature in uppsala seniors (PIVUS) study. Lipids 44: 397-403.

13. Libby P (2012) Inflammation in atherosclerosis. Arteriosclerosis, Thrombosis, and Vascular Biology 32: 2045-2051.

14. Tousoulis D, Oikonomou E, Economou KE, Crea F, Kaske JC (2016) Inflammatory cytokines in atherosclerosis:current therapeutic approaches. Eur Heart J 37: 1723-1735.

15. Corrado E, Rizzo M, Coppola G, Muratori I, Carella M, et al. (2008) Endothelial dysfunction and carotid lesions are strong predictors of clinical events in patients with early stages of atherosclerosis: a 24-month follow-up study. Coron Artery Dis 19: 139-144.

16. Huang PL (2009) A comprehensive definition for metabolic syndrome. Dis Model Mech 2: 231-237.

17. Stolar M (2007) Metabolic syndrome: Controversial but useful. Cleveland Clinic J Med 74: 199-208.

18. Jougasaki M, Ichiki T, Takenoshita Y, Setoguchi M (2010) Statins suppress interleukin-6-induced monocyte chemo-attractant protein-1 by inhibiting Janus kinase/signal transducers and activators of transcription pathways in human vascular endothelial cells. Br J Pharmacol 159: 1294-1300.

19. O Connor M, Salzmann AL, Szabo C (1997) Role of peroxynitrite in the protein oxidation and apoptotic DNA fragmentation in vascular smooth muscle cells stimulated with bacterial interferon-gamma. Shock 8: 439-446.

20. Cai D, Yuan M, Frantz DF, Melendez PA, Hansen L, et al. (2005) Local and systemic insulin resistance resulting from hepatic activation of IKKbeta and NF-kappaB. Nat Med 11: 183-190.

21. Choi K, Kim YB (2010) Molecular mechanism of insulin resistance in obesity and type 2 diabetes. Korean J Intern Med 25: 119-129.

22. Casella S, Bielli A, Mauriello A, Orlandi A (2015) Molecular Pathways Regulating Macrovascular Pathology and Vascular Smooth Muscle Cells Phenotype in Type 2 Diabetes. Int J Mol Sci 16: 24353-24368.

23. Yipeng S, Se-Hyung P, Jinxian X, Sébastien M, Robert N, et al. (2014) IKKß links vascular inflammation to obesity and atherosclerosis. JEM 211: p869.

24. González NH, Vinué A, Vila CM, Fortuño A, Beloqui O, et al. (2008) Molecular mechanisms of atherosclerosis in metabolic syndrome: role of reduced IRS2-dependent signaling. Arterioscler Thromb Vasc Biol 28: 2187-2194.

25. Martínez HS, Vinué A, Núñez L, Andrés BI, Piqueras L, et al. (2014) Insulin resistance aggravates atherosclerosis by reducing vascular smooth muscle cell survival and increasing CX3CL1/CX3CR1 axis. Cardiovasc Res 103: 324-336.

26. Guo S (2014) Insulin signaling, resistance, and the metabolic syndrome: insights from mouse models into disease mechanisms. J Endocrinol 220: T1-23.

27. Lee J, Xu Y, Lu L, Bergman B (2010) Multiple abnormalities of myocardial insulin signaling in a porcine model of diet-induced obesity. Am J Physiol Heart Circ Physiol 298: H310-319.

28. Xi G, Wai C, White MF, Clemmons DR (2016) Down-regulation of Insulin Receptor Substrate 1 during Hyperglycemia Induces Vascular Smooth Muscle Cell Dedifferentiation. J Biol Chem 292: 2009-2020.

29. Dandona P, Aljada A, Mohanty P (2001) Insulin inhibits intranuclear nuclear factor kappa B and stimulates I kappa B in mononuclear cells in obese subjects: evidence for an anti-inflammatory effect? J Clin endocrinol Metab 86: 3257-3265.

30. Isenovic ER, Kedees MH, Haidara MA, Trpkovic A, Mikhailidis DP, et al. (2010) Involvement of ERK1/2 kinase in insulin-and thrombinstimulated vascular smooth muscle cell proliferation. Angiology 61: 357-364.
31. Jeschke MG, Klein D, Bolder U, Einspanier R (2004) Insulin attenuates the systemic inflammatory response in endotoxemic rats. Endocrinology 145: 4084-4093.

32. Heinonen SE, Genové G, Bengtsson E, Hübschle T (2015) Animal models of diabetic macrovascular complications: key players in the development of new therapeutic approaches. J Diabetes Res.

33. Shen GX (2010) Oxidative stress and diabetic cardiovascular disorders: roles of mitochondria and NADPH oxidase. Can J Physiol Pharmacol 88: 241-248.

34. Fiorentino TV, Prioletta A, Zuo P, Folli F (2013) Hyperglycemia-induced oxidative stress and its role in diabetes mellitus related cardiovascular diseases. Curr Pharm Des 19: 5695-5703.

35. Madonna R, De Caterina R (2011) Cellular and molecular mechanisms of vascular injury in diabetes-part I: pathways of vascular disease in diabetes. Vascul Pharmacol 54: 68-74.

36. Kolár F, Jezková J, Balková P, Breh J, Neckár J, et al. (2007) Role of oxidative stress in PKC-delta upregulation and cardioprotection induced by chronic intermittent hypoxia. Am J Physiol Heart Circ Physiol 292: H224-230.

37. Cha JJ, Hyun YY, Jee YH, Lee MJ, Han KH (2012) Plasma leptin concentrations are greater in type II diabetic patients and stimulate monocyte chemotactic peptide-1 synthesis via the mitogen-activated protein kinase/extracellular signal-regulated kinase pathway. Kidney Res Clin Pract 31: 177-185.

38. Holvoet P (2008) Relations between metabolic syndrome, oxidative stress and inflammation and cardiovascular disease. Verh K Acad Geneeskd Belg 70: 193-219.

39. Genel S, Emanuella F, Lucia SM (2015) Metabolic Syndrome-a bomb with delayed reaction. J Bioequiv Availab 7: 155-157.

40. Koba, Hirano T, Kondo T (2002) Significance of small dense low-density lipoproteins and other risk factors in patients with various types of coronary heart disease. Am Heart J 144: 1026-1035.

41. Norata GD, Grigore L, Raselli S (2007) Post-prandial endothelial dysfunction in hypertriglyceridemic subjects: molecular mechanisms and gene expression studies. Atherosclerosis 193: 321-327.

42. Stampfer MJ, Krauss RM, Ma J (1996) A prospective study of triglyceride level, low-density lipoprotein particle diameter, and risk of myocardial infarction. J Am Med Association 276: 882-888.

43. St-Pierre AC, Cantin B, Dagenais GR (2005) Low-density lipoprotein subfractions and the long-term risk of ischemic heart disease in men: 13year follow-up data from the Québec Cardiovascular Study, Arteriosclerosis, Thrombosis, and Vascular Biology 25: 553-559.

44. Norata GD, Raselli S, Grigore L (2009) Small dense LDL and VLDL predict common carotid artery IMT and elicit an inflammatory response in peripheral blood mononuclear and endothelial cells. Atherosclerosis 206: 556-562.

45. Botham KM, Wheeler JCP (2013) Postprandial lipoproteins and the molecular regulation of vascular homeostasis. Prog Lipid Res 52: 446-464.

46. Bao MH, Zhang YW, Lou XY, Xiao Y, Cheng Y, et al. (2014) Puerarin protects endothelial cells from oxidized low density lipoprotein induced injuries via the suppression of LOX-1 and induction of eNOS. Can J Physiol Pharmacol 92: 299-306.

47. Lubrano V, Balzan S (2014) LOX-1 and ROS, inseparable factors in the process of endothelial damage. Free Radic Res 48: 841-848.

48. Lind L, Simon T, Johansson L (2012) Circulating levels of secretory- and lipoprotein-associated phospholipase A2 activities: relation to atherosclerotic plaques and future all-cause mortality. Eur Heart J 33: 2946-2954.

49. Khaybullina ZR (2017) Inflammation and oxidative stress-critical role for metabolic syndrome. J Vasc Med Surg 5: p302.

50. Zhang C, Adamos C, Oh MJ, Baruah J, Ayee MAA, et al. (2016) oxLDL induces endothelial cell proliferation via Rho/ROCK/Akt/p27kip1 signaling: opposite effects of oxLDL and cholesterol loading. Am J Physiol Cell Physiol 313: C340-351. 
Citation: Nazirov FG, Khaybullina ZR, Sharapov NU (2017) Atherosclerosis and Metabolic Syndrome-significance of Inflammation, Urgency of Weight Loss and Extracorporeal Removal of Proinflammatory and Proatherogenic Substances. Cardiovasc Pharm Open Access 6: 227. doi:10.4172/2329-6607.1000227

Page 6 of 6

51. Corrado E, La Greca C, Buccheri D (2011) Subclinical atherosclerosis, inflammation and events. J Cardiology Practice 9.

52. Khaybullina Z, Abdullaeva S (2017) Biomarkers of the Cardimetabolic Risk and System Inflammation in Preobese and Obese Women. J Clin Exp cardiolog 8: p5.

53. Pardo PV, Abraham F, Ashley JW, Minh MH, Deborah AF (2017) Investigating modulation of inflammation in atherosclerosis by complement protein C1q. J Immunol 198: p6.

54. Fraser DA (2017) Complement protein C1q modulates lipoprotein metabolism in macrophage foam cells. J Immunol.

55. Oh MJ, Zhang C, LeMaster E, Adamos C, Berdyshev E, et al. (2016) Oxidized LDL signals through Rho-GTPase to induce endothelial cell stiffening and promote capillary formation. J Lipid Res 57: 791-808.

56. Yan D, He Y, Dai J, Yang L, Wang X, et al. (2017) Vascular endothelial growth factor modified macrophages transdifferentiate into endotheliallike cells and decrease foam cell formation. Biosci Rep 37.

57. Corti R, Fuster V, Fayad ZA (2005) Effects of aggressive versus conventional lipid-lowering therapy by simvastatin on human atherosclerotic lesions: a prospective, randomized, double-blind trial with high-resolution magnetic resonance imaging. J Am College of Cardiology 46: 106-112.

58. Fayad ZA, Mani V, Woodward M (2011) Safety and efficacy of dalcetrapib on atherosclerotic disease using novel non-invasive multimodality imaging (dal-PLAQUE): a randomised clinical trial. The Lancet 378.

59. Marnane M, Prendeville S, McDonnell C (2014) Plaque inflammation and unstable morphology are associated with early stroke recurrence in symptomatic carotid stenosis. Stroke 45: 801-806.

60. Abu FM, Behbehani K, Elkum N (2014) Comprehensive analysis of circulating adipokines and hsCRP association with cardiovascular disease risk factors and metabolic syndrome in Arabs. Cardiovasc Diabetol 9: p76.

61. Nazirov FG, Khaybullina ZR, Khashimov SHKH, Makhmudov UM (2016) Laparoscopic Sleeve Gasterectomy reduces inflammation and cardiometabolic risk in obese patients. Cardiovascular pharmacology: Open Access 5: p200.
62. Khaybullina ZR, Sadikov RA, Azimova MT (2017) Extracorporeal Removal of Low Density Lipoproteins Cholesterol and Middle Molecules from Plasma at Metabolic Syndrome, Possibilities of Cellulose Derivates. J Cardiol \& Cardiovasc Ther 7: 555-719.

63. Morozov AS, Bessonov IV, Nuzhdina AV, Pisarev VM (2016) Sorbents for extracorporeal removal of toxic substances and molecules with adverse biological activity. General Reanimatology 12: 82-107.

64. Altynova EV, Afanaseva OI, Boldyrev AG, Potokin IL, Sokolov AA (2006) Adsorbents for LDL apheresis for blood perfusions. Efferent Therapy 12: 3-14.

65. Afanaseva OI, Altynova EV, Kuznetsov YV, Boldyrev AG, Sokolov AA, et al. (2006) Imnmunohaemosorbents for whole blood perfusion. Efferent Therapy 12: 15-20.

66. Subhapria S, Tomi L, Padmanaban VC (2013). Atherosclerosis: critical role of oxidation and inflammation. Int J Pharmac Sci 5: 5-8.

67. Osto E, Doytcheva P, Corteville C (2015) Rapid and body weightindependent improvement of endothelial and high-density lipoprotein function after Roux-en-Y gastric bypass: role of glucagon-like peptide-1. Circulation 131: 871-881.

68. Kivva VN, Anuphrienko VF, Redkina LV(2001) Methods of apheresis. Patent of Russia Federation 2162344. A61M1/38.

69. Nazirov FG, Khaybullina ZR, Kosnikova IV, Kim VH (2016) Inflammation and reactive oxygen species generation at the peripheral and coronary atherosclerosis, comparative evaluation of its intensity and grade. Am J Cardiovascular and Thoracic Sur 1: p5.

70. Khaybullina ZR, Kosnikova IV (2016) Proimflammatory cytokines and vascular endothelial growth factor levels at the peripheral and coronary atherosclerosis. J Clin Exp Cardiolog 7: p6.

71. Khaybullina Z, Mirjamol Z, Nodir S, Saidariphon M, Saodat A (2017) Oxidative stress-indused effects on proinflammatory cytokines and vascular endothelial growth factor after interventional treatment of coronary heart disease. J Clin Exp Cardiolog 8: p6. 